\title{
Assessment of Knowledge and Attitude of Infection Control among Paramedical Students
}

\author{
Gourav Kumar ${ }^{1}$, Niraj Kumar Sah $^{2}$, Navreet Boora ${ }^{3}$, Raushan Kumar ${ }^{4}$ \\ ${ }^{1}$ M.Sc. (MRIT) Research Follow, Radiological Imaging Techniques, TMU, Moradabad, Uttar Pradesh India. \\ ${ }^{2,3,4}$ Assistant Professor, Radiological Imaging Techniques, Faculty of College of Paramedical Science, TMU, \\ Moradabad, Uttar Pradesh, India.
}

Corresponding Author: Gourav Kumar

\begin{abstract}
Background: Nosocomial contamination control is vital in any medical clinic to keep away from odds of cross-disease or communication of disease to different patients. Mixed breed disease could be characterized as the communication of irresistible specialists among patients and staff inside a clinical atmosphere.

Objectives: 1 . To assess the information and perspectives of paramedical understudies at medical clinics to disease that ought to be followed regularly. 2. To see whether radiography understudies know about the presence of convention and enactment concerning nosocomial contamination control.

Methods: This prospective, questionnaire, comparative study was conducted at College of Paramedical Sciences, Teerthanker Mahaveer University, Delhi road Moradabad, UttarPradesh for period of one year. A validated questionnaire was circulated among Paramedical students. The survey include multiple choice questions (MCQs) related to demographic characteristics (Age, Gender), academic qualification and survey the degree of information and mentality of nosocomial contamination control among paramedical understudies.

Result: In this study assessment the knowledge and attitude of Infection control among paramedical students and we have concluded the exact mean value of all respondent in which there positively correct answer according to included three programmes like radiological imaging techniques, Medical lab techniques, and Optometry and in which there were response for radiological imaging techniques $(73 \%)$, Medical
\end{abstract}

Lab Techniques (88\%) and Optometry (82\%). So then we concluded that Medical lab techniques have more knowledge compared to radiological imaging techniques and Optometry. The result of this study was not satisfied knowledge of respondents. Study concludes that there should be proper lecture and theory classes for the conduction of knowledge about nosocomial infection control. Among all three courses, Radiology imaging techniques, medical lab techniques, and Optometry, in 374 participants, and in which participated students have knowledge about paramedical students are at risk of infection $79.1 \%$ of students correct answered and the $20.9 \%$ students gave incorrect answered .

Conclusion: Among all the subjects, most of them were aware and had a positive attitude toward (78\%) nosocomial infection control. The knowledge of nosocomial infection control was good among the respondents since most of them have done undergone prior nosocomial infection academic or performed nosocomial infection control by self-precautions. The respondents had good knowledge for nosocomial infection control and we were involved in three programmes of paramedical college including Radiological imaging techniques, Medical lab techniques, and Optometry and in which entire participants were 374 and in which $78 \%$ were positive knowledge and $22 \%$ negative knowledge.

Keywords: Infection, Microorganism, Sterilization, Nosocomial infection, PPE, SICP, PUI. 


\section{INTRODUCTION}

Nosocomial infection is hospital acquired infection like bacteria, viruses, and fungi etc. these are caused in any events 48 to 72 hours after admission to emergency clinic or during a predetermine of 3 to 10 days after excuse so patient should not show side effect of disease at the time of admission. ${ }^{1}$

Numerous elements are related with a high risk of nosocomial infection the factor that can minimum risk of nosocomial infection include systemic treatment of patients avoided prolong hospitalization the utilization of antimicrobial for hand cleaning. ${ }^{1}$

Nosocomial infection are a significant medical condition in all social orders as indicated by the WHO 7.1 million instances of nosocomial contamination happen each year. One out of each 20 individuals experiences clinic disease which prompts 99,000 instances of death consistently and forces an assessment cost of 32 million to society. ${ }^{1}$

Keeps to SICP (Standard infection control precaution) by the paramedical understudy is basic in battle HAIs (hospital acquired infections). Hence, radiography understudies need to have fitting information and practices of disease control.

Contamination control is connected with shut down or stops the spread of disease in medical care establishments. Radiology staff in emergency clinics oversees various patients every day. Those patients who have a disease can put the radiology staff in danger when they visit the division they can likewise be a wellspring of tainting in the radiology field like surfaces, instruments, and machines. ${ }^{3}$

Staff of Paramedical is at high risk of openness cross-disease by blood borne microbes, for example, mycobacterium tuberculosis and other viruses.

Hand cleanliness forestalls crossdisease in clinics however adherence to rules is regularly poor. While the strategy engaged with hand cleanliness is basic, the unpredictable association of components that the investigation of hand cleanliness conduct produces the investigation of hand cleanliness complicates. ${ }^{4}$

\section{Function of Infection Control Program}

- Education and input to clinicians utilizing observation information and antibiogram information by anatomic site

- Provision of either hand washing materials or liquor based (waterless) hand purifying materials.

- Monthly meeting of the contamination control group.

\section{Three moments for hand hygiene}

1. Before contacting a patient.

2. Immediately after contact with body liquids, discharges mucous films nonflawless skin, or wound dressings whether or not gloves were utilized.

3. After reaching a patient and his/her brief natural components, regardless, when leaving the patient's side.

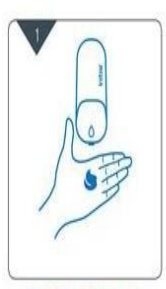

Wet hands and

apply soap

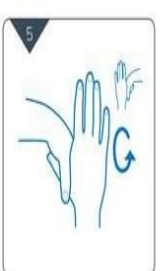

Clasp each hand around opposing thumb and rub in rotational manner

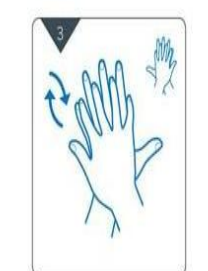

Fingers interlaced, rub hands together, then right

palm to back of left hand and rub side to side and vice versa

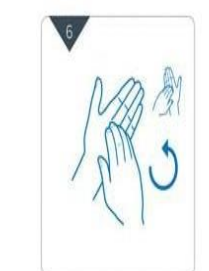

Rotational rubbing in both directions by placing fingertips of each hand in

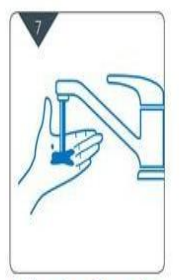

Rinse hands under running water
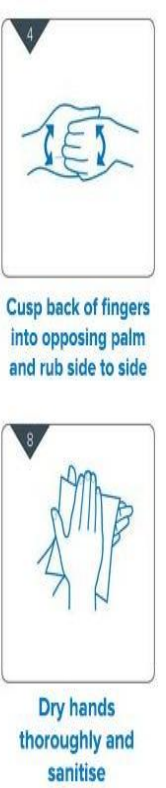

\section{Individual Protective Equipment}

\section{Utilization of Gloves}

Sterile gloves ought to be worn when contacting blood, body fluid, 
discharges, and debased things and when acting venipuncture.

\section{Eye Insurance, Face Cover and Face Safeguard}

Face Cover should be worn during systems or patient consideration.

Splashes of blood, body liquids emissions. Model suctioning imaging an injury.

Research facility tests.

\section{N95 Respirators}

Respirators are wrapper unequivocally expected to channel little particles transmitted by the airborne course like measles, tuberculosis and varicella. They are used for disintegrated making frameworks that have been seemed to uncover staff, including:

- Diagnostic bronchoscopy

- Sputum acceptance

- Laboratory treatment of mycobacterium tuberculosis, for example, concentrating respiratory examples for smear and culture Staff needed to wear N95 respirators should go through fitting.

\section{Outfit/Cover}

Outfit/cover ought to be worn to secure skin and to forestall ruining of dress during systems or patient consideration exercises that are required to create sprinkles or showers of blood, body fluid, emissions, and discharges.

\section{Hack decorum/respiratory cleanliness}

Instruct characteristic individuals and clinical benefits workers to cover their mouths/noses while hacking or wheezing use and dispose of tissues, perform hand neatness after hands have been in contact with respiratory outflow. ${ }^{5}$

\section{METHOD AND MATERIAL}

STUDY TYPE: A questionnaire-based cross-sectional study was carried out in the college of paramedical sciences at Teerthanker Mahaveer University, Delhi Road Moradabad, and Uttar Pradesh, India.
This study was a questionnaire based on Assessement of Knowledge and Attitude of Infection Control among Paramedical Students. To check the Knowledge about Nosocomial infection control postgraduate and undergraduate students from three departments' i.e. radiological imaging techniques, medical lab techniques and optometry.

STUDY DESIGN: This study was prospective, comparative \& questionnairebased designed and carried Out among paramedical students of the College of Paramedical Sciences at Teerthanker Mahaveer University Delhi Road Moradabad To check Knowledge about Nosocomial infection control postgraduate and undergraduate students from three departments i.e. radiological imaging techniques, medical lab techniques, and optometry were compared. The project was approved by the college review committee.

STUDY AREA: Students coming to pursue degree \& master in the college of paramedical sciences Teerthanker Mahaveer University Delhi Road Moradabad Uttar Pradesh, India.

STUDY DURATION: This questionnairebased study was carried out for the period of one year from 1 May 2020 to 1 May 2021at the College of Paramedical Sciences Teerthanker Mahaveer University Delhi Road Moradabad Uttar Pradesh.

\section{SELECTION CRITERIA}

- Inclusion Criteria

1. 1st-year undergraduate students of RIT, MLT \& Optometry

2. 2nd-year undergraduate students of RIT, MLT \& Optometry

3. 3rd-year undergraduate students of RIT, MLT \& Optometry

4. 1st-year postgraduate students of RIT, MLT \& Optometry

5. 2nd-year postgraduate students of RIT, MLT \& Optometry

6. Students who are willing to participate 


\section{- Exclusion Criteria}

1. Faculty member of the paramedical college.

2. All diploma students.

STUDY POPULATION: The size of the population was 374 students. The population consisted of all students including both male \& female who were physical \& mentally sound aged between 18-31 of three departments i.e. radiological imaging techniques, medical lab techniques, and optometry of paramedical science excluding the candidates who fell under exclusion criteria.

\section{METHOD OF DATA COLLECTION:}

The study was carried out among students of three departments of paramedical science i.e. radiological imaging techniques, medical lab techniques, and optometry excluding the candidates who fell under exclusion criteria and who were ready to participate were included in the study. The purpose of the study was explained to every individual. After assessing these criteria, a total number of 374 participants were included in the study. Verbal consent was obtained from all students included in this study. The questionnaire was structured by using Google form \& was distributed in different WhatsApp groups via the internet. The questions were incorporate subsequent to going through various literature related to that, which comprised of a self-structured questionnaire divided into two sections. The first section of the questionnaire comprised of demographic data including name, age, gender, program, department and semester.

SETTING AND RESOURCE: The project setting was done in the College of Paramedical Sciences Teerthanker Mahaveer University, located in the area of Moradabad district of Uttar Pradesh, India. This University is well established with various paramedical courses with various programs required for this study including radiological imaging techniques, medical lab techniques, and optometry.
Statistical Analysis: The data collected was compiled, tabulated, and analyzed. Analysis was done using Google form.

\section{RESULT}

A prospective, comparative \& questionnaire- based study was carried out with the size of 374 students on the topic "Assessments of knowledge and attitude of infection control among paramedical students". Gave the following results in which pie chart

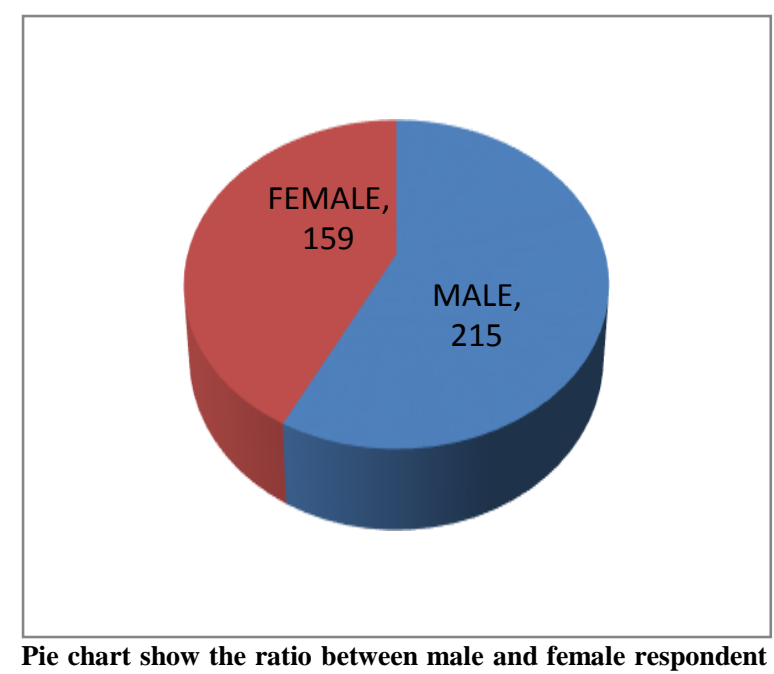
in three paramedical programme

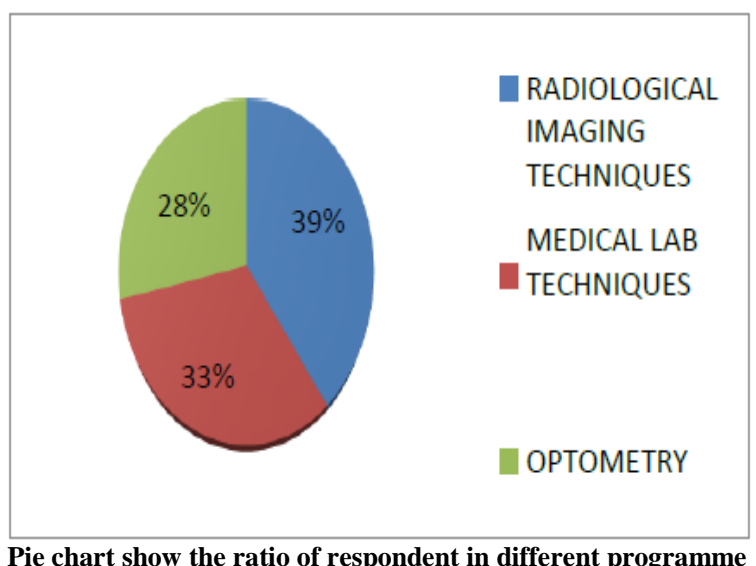

After collecting data values were statistically and tabulated. Among the groups, the sample size was more in the radiological imaging techniques 143 students respectively. Less sample size was seen in 118 from medical lab techniques, 102 from Optometry students Pie chart show the ratio of radiological imaging techniques in the college of paramedical 
sciences was more in comparison to the Optometry and Medical lab techniques.

The knowledge of nosocomial infection control was good among the respondents since most of them have done undergone prior nosocomial infection academic or performed nosocomial infection control by self-precautions. The respondents had good knowledge for nosocomial infection control and we were involved in three programmes of paramedical college including Radiological imaging techniques, Medical lab techniques, and Optometry and in which entire participants were 374 and in which $78 \%$ were positive knowledge and $22 \%$ negative knowledge.

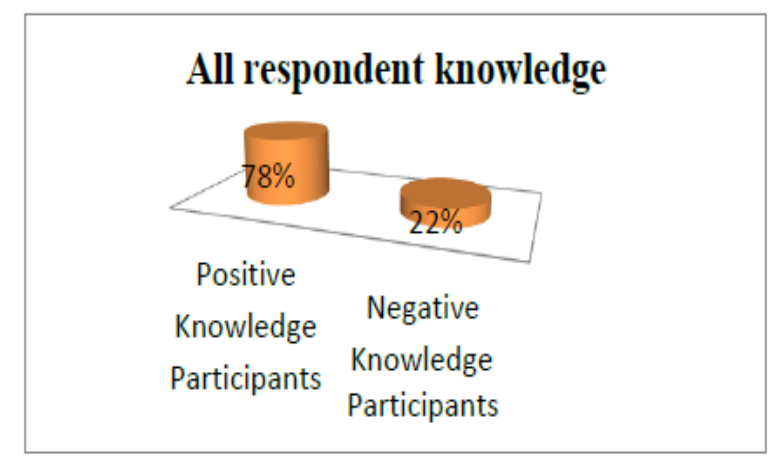

Pie chart show all participants negative and positive knowledge

In this study assessment the knowledge and attitude of Infection control among paramedical students and we have concluded the exact mean value of all respondent in which there positively correct answer according to included three programmes like radiological imaging techniques, Medical lab techniques, and Optometry and in which there were response for radiological imaging techniques (73\%), Medical Lab Techniques $(88 \%)$ and Optometry (82\%). So then we concluded that Medical lab techniques have more knowledge compared to radiological imaging techniques and Optometry. The result of this study was not satisfied knowledge of respondents. Study concludes that there should be proper lecture and theory classes for the conduction of knowledge about nosocomial infection control.

\section{DISCUSSION}

In this study Assessment the Knowledge and Attitude of Infection Control Among Paramedical Students and we were concluded the exact mean value of all respondent in which there positively correct answer according to included three programmes like radiological imaging techniques, Medical lab techniques, and Optometry and in which there were response for radiological imaging techniques $(73 \%)$, Medical Lab Techniques $(88 \%)$ and Optometry $(82 \%)$. So then we concluded that Medical lab techniques have more knowledge compared to radiological imaging techniques and Optometry. The result of this study was not satisfied knowledge of respondents. Study concludes that there should be proper lecture and theory classes for conduction of knowledge about nosocomial infection control. ${ }^{6}$

\section{CONCLUSION}

The paramedical students had great Information with respect to nosocomial contamination control and this information was reflected in their mentality and disposition and practice close by cleanliness for the counteraction of nosocomial disease. nonetheless, this investigation appear that there is a requirement in order to additional development in the need of hand cleanliness preparing program and The instructional courses ought to be led all the more over habitually with persistent execution input As paramedical understudies are a significant gathering of major parts in the medical care group it is critical to give the best precise information and legitimate preparing in regards to the preventive proportions of nosocomial contamination from the early time of their preparation further there is need for a disease anticipation group to get more engaged with preparing and refreshing of existing practices. Hand cleanliness specialists and sink are the vital components in improving execution to hand hygiene. ${ }^{6}$

Acknowledgement: None 


\section{Conflict of Interest: None}

\section{Source of Funding: None}

\section{Ethical Approval: Approved}

\section{REFERENCES}

1. Hamed Sarani, Abbas Balouchi, et.al Knowledge Attitude and Practice of Nurses about standard precaution for Hospital Acquired infection in Teaching Hospital Affiliated to Zabal University of Medical Sciences (2014) pregnancy Health Research Centre Zahedan University of Medical Sciences Global Journal of Health Science vol.8 Page No.193-198,No. 3, 2016, 201506-23.

2. D.Nyirenda, W. Ten Ham-Baloyi et.al Knowledge and Practice of radiographer regarding infection control in the radiology department in Malawi ELSIVIER 2018-0108 P 1-5.

3. Muhammad A.Halwani, Hossam M. EIHawary et.al Knowledge and attitude of infection Prevention Measures among Radiology Staff in AI Baha University KSA, Ommega Online Publisher 2017-0126, vol.02, P41-47.

4. Sunita R Bhandari, Sanjeev Vinayak Rairkar et.al Knowledge and Attitude of Paramedical Staff and hospital Support staff regarding Hospital infection Control Professor and HOD Department of Microbiology, SMBT Institute of Medical Sciences and Research Centre Igatpuri, Nasik Maharashtra. J Cont. Med A Dent. 2016-01-14 vol.04, P 31-35.

5. Hospital Infection Prevention And Control Guidelines Dr. S. Venkatesh, Director, National Centre for Disease Control,22Sham Nath Marg, Delhi.

6. Ishwari Sharma Paudel, Vivek Ghosh, et.al Knowledge Attitude and practice of nursing Students on hospital Acquired Infection in the western region of Nepal. School of Public Health and Community Medicine B.P.Koirala Institute of Health Science, Dharan Gandaki Medical College Teaching Hospital Pokhara. Journal of College of Medical Sciences Nepal vol.12 No.3 Julysept.016,2016-09-02.

7. Rania Mohammad Ahmad, Reem ALZahrani et.al Knowledge Attitude and Practices of infection control among the
Radiology Departments, Taif Saudi Arabia, Radiology Department, Faculty of Applied Medical Science and Research (IJSR) 201711-11 vol.06, P709-714.

8. SFA Bribe, B Ordinioha et.al Knowledge attitude and infection Control practices of two tertiary hospitals in Port Harcourt, Nigeria Department of Family Medicine, Niger Detta University Teaching Hospital, okolobiri, Bayelsa state, Nigeria. Nigerian Journal of Clinical Practice. 2014-04-02 vol.17 P691-695.

9. Mozhgan Kalantarzadeh et.al Knowledge and practice of Nurses about the control and prevention of nosocomial Infection in Emergency Departments Arch Clin Infect Dis. 2014, 9(4):e18278.

10. Prabhakar SM et.al Knowledge Attitude and Practice Regarding Nosocomial Infections among General Health Practitioners and Medical College Students. Professor Depart. Of General Medicine SMBT Institute of Medical Sciences \& Research Centre, Dhamagoon Tal, Igatpuri, Dist. Nasik, Maharashtra, India .

11. Jamila Mohammad Hassan, Goni Musa Mohammad et.al The Practice Of Universal Precautions Among Student Radiographers In Their Clinical Phase Of Training Department of Medical Radiography College of Maiduguri Nigerian Journal of Medical Imaging and Radiation Therapy. 2018-11-01 vol.07, P 58-67.

12. William KnodwoAntwi, Kofi AdesiKyei et.al infection control by Radiographers during Radiological Examination in Ghana Department of Radiography college of health Sciences Greater Accra, Accra, Ghana World Journal of Medical Research 2015-04-26 vol.08 P-1

13. J Ojulong, KH Mitonga et.al Knowledge and attitudes of infection prevention and among health sciences students at the university of Namibia Articles from African health sciences are provided here courtesy of makere university medical school 201312- 13, vol. (4), P1-8.

14. Sher Bahadur, Attaullah Jan et.al. Infection Prevention And Control Practices Observed By Students Of A Medical College 201705-10 J Rehman Med. Inst. Vol.(3),P38-45.

15. Biruk Bayleyegn Addisu mehari et.al department of clinical Hematology and Health Sciences University of Gondar Knowledge Attitude and Practices on 
Hospital Acquired Infection Control and Association Factor Among Healthcare Workers at University of Gondar Comprehensive Specialized Hospital Northwest Ethiopia 2019-01 to 2019-06 P 259-265.

16. Ruwan Duminda Jayasinghe and Bimali Sanjeevani Weerakoon Department of oral medicine and periodontology Faculty of Dental Sciences University of Paradeniya Sri Lanka Prevention of nosocomial infection and Standard precaution knowledge and practice among radiographers in Sri Lanka 2014-02-12 journal of Medical and Allied Sciences P . 09-13.
17. JB Suchita, N Lakshmi Devi et.al Department of Microbiology Mysore University Mysore 570006 Karnataka India Impact of education on Knowledge attitudes and practices among various categories of healthcare workers on nosocomial infections 2007-02-10, Indian Journal of Medical Microbiology, vol. (25), P. 181-187.

How to cite this article: Kumar G, Sah NK, Boora $\mathrm{N}$ et.al. Assessment of knowledge and attitude of infection control among paramedical students. International Journal of Research and Review. 2021; 8(6): 340-346. DOI: https://doi. org/10.52403/ijrr.20210643 